\title{
Production of Biopolymer Foams Based on Polylactic Acid Plasticized With Lactic Acid Oligomer
}

\author{
Katalin LITAUSZKI, ${ }^{1}$ Ákos KMETTY ${ }^{1,2}$ \\ ${ }^{1}$ Budapest University of Technology and Economics, Faculty of Mechanical Engineering, Department of \\ Polymer Engineering. Budapest, Hungary, litauszkik@pt.bme.hu \\ ${ }^{2}$ MTA-BME Research Group for Composite Science and Technology. Budapest, Hungary, kmetty@pt.bme.hu
}

\begin{abstract}
In our work, we modified polylactic acid biopolymer using oligomeric lactic acid. We have successfully plasticised polylactic acid compounds with 5, 10, $20 \mathrm{wt} \%$ oligomeric lactic acid using a liquid dosing system connected to a compounder extruder. The produced compounds were foamed with an exothermic chemical foaming agent. The density of the foams was measured and the fracture surfaces were examined by electron microscopy to assess the homogeneity of the cell structure. Based on this, we believe that the plasticising effect of oligomeric lactic acid is undeniable, but a processing temperature of $190{ }^{\circ} \mathrm{C}$ is not optimal for the foaming process. In the future, the production of biopolymer foam structures with a higher density reduction can be achieved by reducing and optimizing the foam processing temperature.
\end{abstract}

Keywords: poly lactic acid, plasticised, extrusion, foam.

\section{Introduction}

Nowadays, polymers play a very important role. In 2019368 million tons of polymer raw material was produced [1]. The high use of polymers, almost $40 \%$ in the case of packaging, raises serious waste management issues. Biopolymers offer a potentially promising raw material type in terms of environmental impact. Biopolymers are biodegradable polymers that can be produced from a renewable resource, but are also biodegradable. Because of these benefits, they are at the forefront of research into promising alternatives to petroleum-based polymers, specifically for shortlife-cycle products. Polylactic acid (PLA) is one of the most promising biopolymer feedstocks, being produced in large quantities (140,000 tonnes/ year), thus having a relatively low price ( $\sim 2 / \mathrm{kg}$ ) compared to other biopolymers [2], in addition it can be processed with conventional polymer processing equipment. In order to expand the applicability of polylactic acid, it is necessary to modify its disadvantageous properties. One of the biggest disadvantages of PLA is its brittleness and low elongation at break. A suitable method to improve these properties is the internal or external plasticisation of PLA. In this case, after polymerization, the properties of the polymer are modified without any chemical reaction. In a system internally plasticised in this way, we did not change the polymer chain but the plasticizer molecules are incorporated between the polymer chains that interact with the polymer molecules, thus changing the PLA's properties [3]. In connection with the plasticisation of PLA, several plasticizers have been tested, such as poly (ethylene glycol) with different molecular weights $[4,5]$ and citrate ester [5]. One of the most promising plasticizers is the oligomeric version of polylactic acid itself. The repeating unit of oligomeric lactic acid (OLA) and PLA is the same, the only difference is in the number of repeating unit, i.e. in its molecular weight. While an average polymer contains repeating unit in the order of one hundred thousand, in the case of oligomers it is only a few thousand, therefore their molecular weight is lower. The production of polylactic acid-based foam, the reduction of the brittleness of the produced foams and the increase of their energy absorption capacity are still actively researched areas. In terms of foaming, the less well-researched chemical foaming is 
typically carried out with an exothermic foaming agent [6]. The most common exothermic foaming agent is azodicarbonamide [6]. One of the advantages of the chemical foaming process is that it is not necessary to modify the extruder. Blending polylactic acid with oligomeric lactic acid may be suitable for reducing the brittleness of foam, so foaming of PLA/OLA blends may be the focus of particular interest.

\section{Materials, processing and methods}

For the experiment, we selected NatureWorks LLC's Ingeo 4032D biopolymer. This polylactic acid is recommended for extrusion processing. The D-lactide content of this PLA is $1.4 \%$ and it is a crystalline polymer [7]. It has a density of $1.24 \mathrm{~g} / \mathrm{cm}^{3}$ [8]. The lactic acid oligomer was Glyplast OLA 2 manufactured by Condensia with ester content $>99 \%$. Its density is $1.10 \mathrm{~g} / \mathrm{cm}^{3}$. Its viscosity at $40^{\circ} \mathrm{C}$ is $90 \mathrm{mPas}$. The selected OLA type was added to the PLA at 5, 10 and $20 \%$ by weight. The foaming agent was Tracel IM 3170 MS, manufactured by Tramaco $\mathrm{GmbH}$, in the form of granules. This foaming agent is an exothermic chemical foaming agent containing azodicarbonamide (ADCA). Its thermal decomposition is between 147 and $212{ }^{\circ} \mathrm{C}$ [9].

For compounding we used a Labtech LTE 26-44 twin-screw extruder equipped with a Labtech IZ120/VS liquid dispenser, which was used to deliver the liquid directly into the melt. The plasticiser was preheated to $70^{\circ} \mathrm{C}$. OLA was injected into the polylactic acid melt at the 3rd zone of the twin screw extruder to promote homogeneous mixing. The temperature profile was 180/185/185/190/190 $/ 190 / 195 / 195 / 200 / 200 / 200{ }^{\circ} \mathrm{C}$. The extruder screw speed was $25 \mathrm{rpm}$ and the feeder speed was $8.5 \mathrm{rpm}$. The extruded cord was granulated with a Labtech LZ-120/VS type granulator, which was used as a raw material for the extrusion foaming. In each case, the raw materials were dried at $80^{\circ} \mathrm{C}$ for 6 hours before manufacture using a WGL-45B (Huanghua Faithful Instrument Co., China) dryer.

A Collin Teach-Line ZK-25T twin-screw extruder was used to produce the foam. Based on our preliminary experiments [10], Tracel IM $3170 \mathrm{MS}$ type CBA was mixed with $2 \%$ by weight of PLA granules by dry mixing. The temperature profile was $155 / 160 / 175 / 190 / 190{ }^{\circ} \mathrm{C}$. The screw speed was $10 \mathrm{rpm}$.

Differential scanning calorimetry (DSC) measurements were performed using TA Instruments Q2000 DSC equipment. The test temperature range was (-20) to $200{ }^{\circ} \mathrm{C}$, which was determined based on the expected glass transition temperature according to the literature. The heating rate was $5{ }^{\circ} \mathrm{C} / \mathrm{min}$. The weights of the samples were between 3 and $6 \mathrm{mg}$. The measuring atmosphere was nitrogen.

Thermogravimetric analysis (TGA) was performed using TA Instruments Q500 equipment. The temperature range was 50 to $600^{\circ} \mathrm{C}$. The heating rate was $10^{\circ} \mathrm{C} / \mathrm{min}$. The weight of the samples was between 3 and $6 \mathrm{mg}$. The measuring atmosphere was industrial grade air at a flow rate of 60 $\mathrm{mL} / \mathrm{min}$.

An AR2000 type oscillation rheometer manufactured by TA Instruments (USA) was used for rheological analysis of the raw materials. The measurement was performed between parallel discs of steel. The test temperature was $190^{\circ} \mathrm{C}$. The tested frequency range was $1-100 \mathrm{~Hz}$, the applied stress was $10 \%$. The diameter of the specimen was a $25 \mathrm{~mm}$ with the thickness of 1-2 mm.

We created a cryogenic fracture surface of the foam structures therefore, we were able to examine the cross section of the foams. We created scanning electron microscopy (SEM) images. SEM images were taken with a JEOL JSM 6380LA scanning electron microscope manufactured by Jeol Ltd. We used an accelerating voltage of $10 \mathrm{kV}$. The cryogenic fraction surface of the samples was coated with a gold-palladium alloy under vacuum with an Argon gas purge at $10 \mathrm{~mA} / \mathrm{Pa}$.

The density of the compounds and foams was measured with a $10 \mathrm{ml}$ graduated cylinder in $0.1 \mathrm{ml}$ increments. The measuring medium was distilled water. We used an OHAUS Explorer type of balance with a weighing range of $110 \mathrm{~g}$ and a measuring accuracy of $0.1 \mathrm{mg}$.

Cell population density $\left(N_{c}\right)$ was calculated based on Equation (1), where $n$ is the number of cells in the microscopic image of the fractured surface, $M$ is the magnification, and $A$ is the cross section of the foam $\left[\mathrm{cm}^{2}\right]$. ER denotes expansion [11].

$$
N_{c}=\left(\frac{n \cdot M^{2}}{A}\right)^{\frac{3}{2}} \cdot E R
$$

\section{Characterisation of the compounds}

We performed several measurements on the produced compounds to evaluate their morphological, thermal, and rheological properties. The morphology of the manufactured compound was evaluated by DSC analysis to investigate the effect of plasticizer content on the glass transition $\left(T_{g}\right)$, cold crystallization $\left(\Delta H_{c c}\right)$ and crystal melting $\left(T_{m}\right)$ 
temperatures. The resulting set of DSC curves is shown in Figure 1, which shows the DSC curves obtained during the first heating of compounds softened to varying degrees of OLA. One of the easy-to-detect and quantifiable properties of plasticizers is that the glass transition temperature is shifted to a lower temperature. There is a clear tendency for the glass transition temperature to shift towards lower temperatures, and the peak temperature for cold crystallization and the peak temperature for crystal melting show a similar trend. This effect was observed as a result of plasticising with OLA. The $T_{g}$ change is the biggest in the case of $20 \mathrm{wt} \%$ OLA content (from $61{ }^{\circ} \mathrm{C}$ to $26^{\circ} \mathrm{C}$ ) as expected.

Furthermore, with the addition of $5 \mathrm{wt} \%$ OLA, it can be observed that no glass transition temperature $\left(62{ }^{\circ} \mathrm{C}\right)$ has occurred as a result of this OLA addition. Compared to its results in the literature, we managed to achieve a lower $T_{g}$ than reported by Sinclair [12], but we failed to achieve the glass transition temperatures of 37 and $18^{\circ} \mathrm{C}$ described by Martin and Avérous with the addition of 10 and $20 \mathrm{wt} \%$ OLA, respectively [13]. The $T_{g}$ temperature between $36-40{ }^{\circ} \mathrm{C}$ was achieved by Burgos et al. with the use of $15 \mathrm{wt} \%$ OLA. These values are consistent with our measurement results.

The TGA curves of the compounds made of PLA and PLA/OLA are shown in Figure 2. As we added lower molecular weight chains to our PLA matrix in the form of oligomeric lactic acid the temperature at the initial $5 \%$ weight loss is decreased as we expected. The reason for this is that these lower molecular weight chains are more mobile and decompose under lower temperature. It is also important to note that the temperature for $50 \%$ weight loss changed only slightly, in which case the curves run together with only a small deviation and their final decomposition temperature is the same, so these values are related to the PLA values and do not depend on plasticizer content.

Adequate melt strength is of paramount importance during foaming, since with low melt strength the polymer matrix cannot retain the formed cells, they collapse. In contrast, if the melt strength is too high, the foaming agent will not be able to expand the nucleated cell sufficiently. Therefore, the viscosity of the manufactured compounds was investigated. Figure 3 shows the absolute value of the complex viscosity of compounds made from PLA as a function of angular velocity. The values corresponding to an angular velocity of $100 \mathrm{rad} / \mathrm{s}$ have been highlighted, as this value corresponds in order of magnitude to

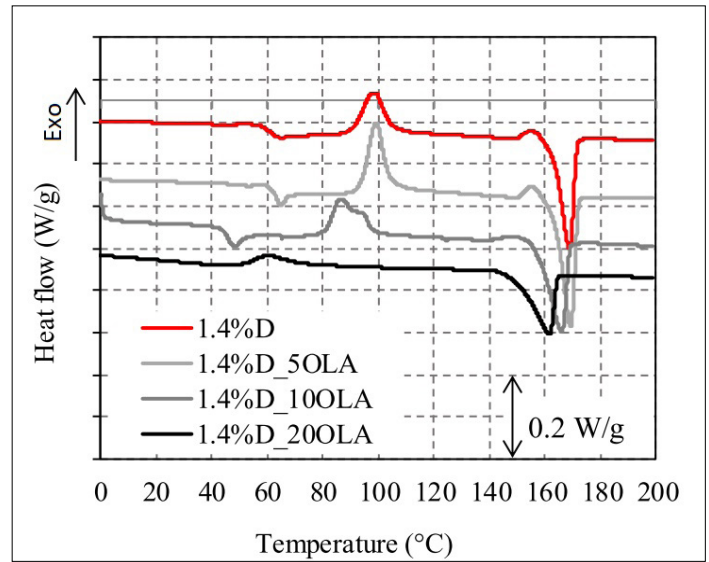

Figure 1. Heat-flow curves as the function of temperature in the case of PLA and OLA containing samples based on DSC measurements.

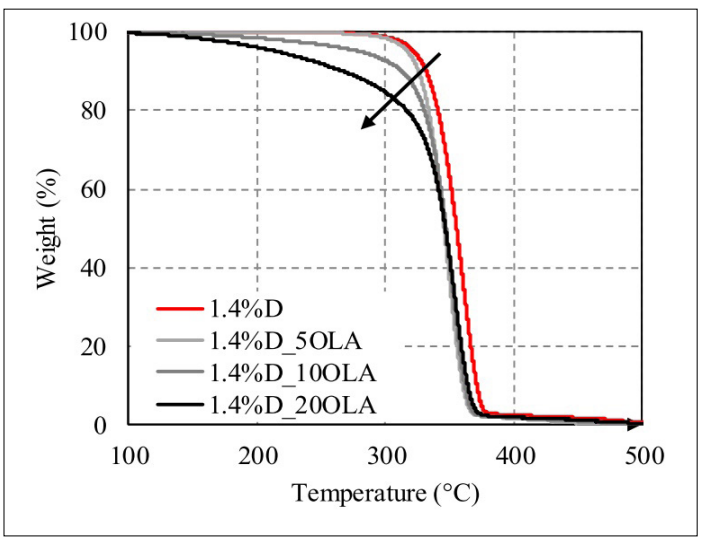

Figure 2. Weight loss curves as the function of temperature in the case of PLA and OLA containing samples based on TGA measurements.

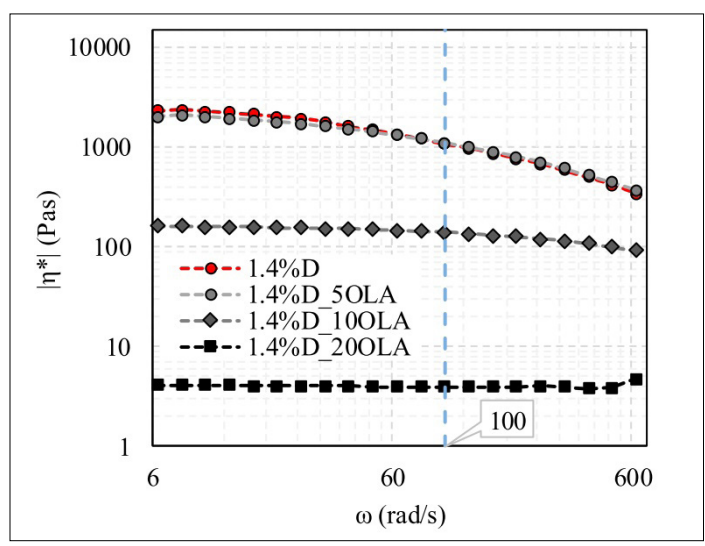

Figure 3. Complex viscosity curves as the function of angular velocity in the case of PLA and OLA containing samples based on oscillation rheometer measurements. 
the shear rate occurring during extrusion. This $100 \mathrm{rad} / \mathrm{s}$ is lower than the shear rate of an average extrusion, but due to the low screw speed, it can be approximated in this case. It can be observed that the addition of $5 \mathrm{wt} \%$ OLA does not significantly affect the viscosity of the sample, in contrast to the $10 \mathrm{wt} \%$ and $20 \mathrm{wt} \%$ compounds, a significant decrease results, it can be concluded that a compound containing $5 \mathrm{wt} \%$ of OLA is expected to be suitable for stable foaming, and it is possible to form a foam from the system containing $10 \mathrm{wt} \%$ of OLA with other foaming agents at lower temperatures.

\section{Characterisation of the compounds}

During foaming, reference samples and PLAbased foams containing $2 \mathrm{wt} \%$ CBA were produced in a continuous operation with a twinscrew extruder. We first examined the density of the foams. The results of the density measurements are shown in Figure 4. There is a clear tendency that an increase in plasticiser content causes an increase in density due to the effect of OLA on viscosity. The lower polymer melt strength is unable to maintain the cell structure, so they collapse and coalesce. The mixture containing $20 \mathrm{wt} \%$ OLA also proved to be unmanageable, unprocessable during foaming. The lowest density was obtained with the PLA without OLA using $2 \mathrm{wt} \%$ CBA $\left(0.6 \mathrm{~g} / \mathrm{cm}^{3}\right)$.

Figure 5 shows scanning electron micrographs of cryogenic fractured surfaces of foams. The effect of the increasing plasticizer content on viscosity can be observed. Compared to the reference foam, $5 \mathrm{wt} \%$ OLA did not significantly change the cell structure, but $10 \mathrm{wt} \%$ plasticizer reduced the

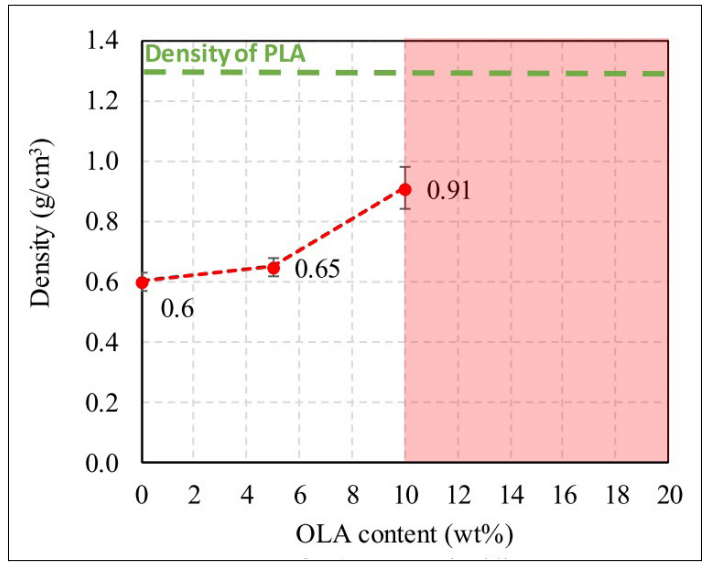

Figure 4. Density results of foams containing PLA and OLA as a function of OLA content. melt viscosity of the polymer to such an extent that the collapse of the cells led to the formation of the giant bubble shown in the picture and the production was not continuous. The melt could not contain the generated foaming gas. It can also be observed that as a result of cooling, smaller cells formed in an outer layer, while larger cells could form inside the sample because, they did not solidify as quickly as the outer ones.
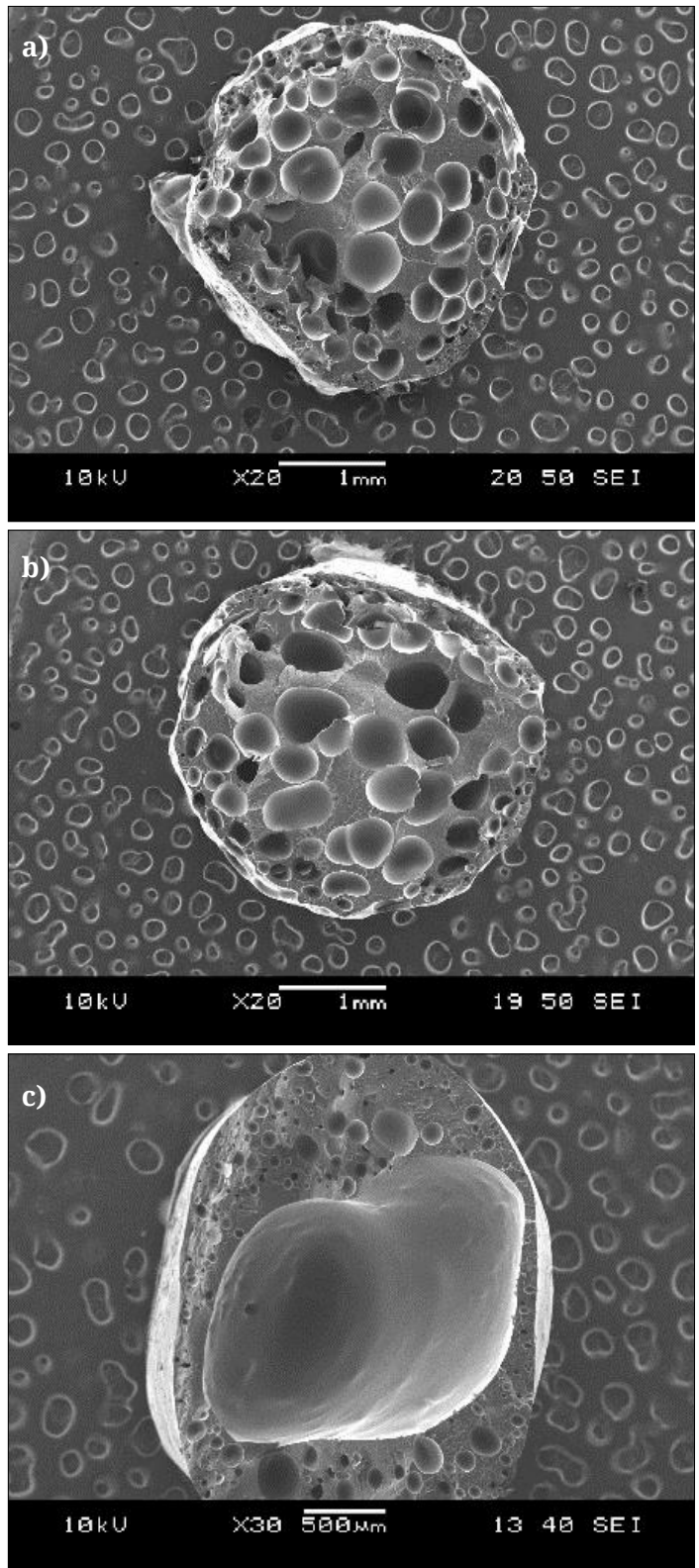

Figure 5. SEM imaged of foams from top to bottom: with a) 0,b) 5, c) 10 wt\% OLA content. 


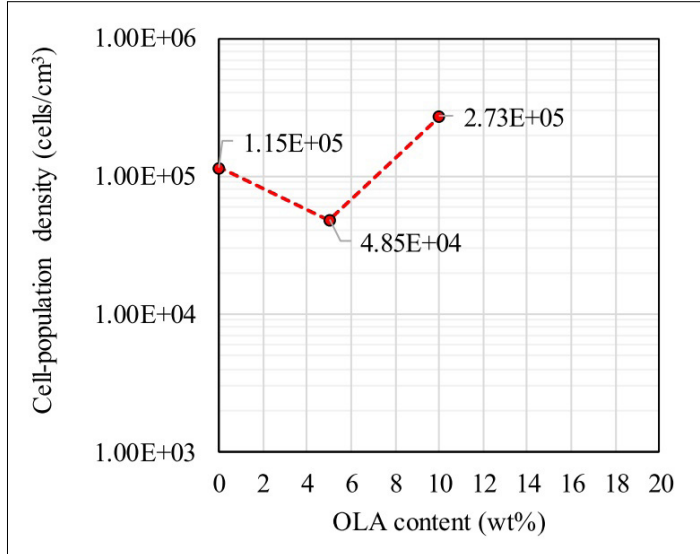

Figure 6. The cell-population density values of foams containing $0,5,10 w t \%$ OLA.

Based on SEM images, cell population density was calculated. Figure 6 shows the cell--population density as a function of OLA content. The highest cell population densities resulted in the samples containing $10 \mathrm{wt} \%$ OLA, and then, with slightly lower cell population densities in the case of reference foam. The cell-population densities calculated by us achieved a cell-population density of the order of $10^{5}$, which was in the same order that was achieved by Julien et al. in the case of chemically foamed PLA [14]. However, this alone does not characterise the foamed structures. It should be treated in conjunction with SEM images, because it does not provide specific information on the homogeneity, size and distribution of the cell structure. In this case, this will be especially true. Since at $10 \mathrm{wt} \%$ OLA dosing a large number of small cells were formed, but no homogeneous foam structure was formed. However, at a dose of $5 \mathrm{wt} \%$ OLA, the cell structure shows a favourable homogeneity.

\section{Conclusions}

We successfully produced PLA compounds plasticised with 5, 10, 20wt\% OLA using a liquid dispenser. We pointed out, using DSC measurements, that the glass transition temperature-lowering effect of OLA is in line with the results presented in the literature. The highest rate of $T_{g}$ reduction was achieved at $20 \mathrm{wt} \%$ OLA administration $\left(26^{\circ} \mathrm{C}\right)$. This shift was also observed at in the case of $T_{c c}$ and $T_{m}$. Thermogravimetric analysis was used to examine the thermal stability of the manufactured compounds and, as expected, their decomposition temperatures shifted in the direction of the lower ones under the influence of OLA.
Furthermore, rheological measurements were performed to characterise the viscosity of the different PLA/OLA formulations, as this is closely related to the foamability of the given compound. Rheological measurements and subsequent foamability were consistent with each other. The density of the formed foams were measured, and the fracture surfaces were examined by scanning electron microscopy to assess the homogeneity of the cell structure and the cell-population density. Based on all this, it is believed that the plasticisation efficiency of OLA is undeniable, but the processing temperature of $190{ }^{\circ} \mathrm{C}$ is not suitable for foaming PLA/OLA compounds. In future, reducing and optimizing the production temperature could be a promising step forward.

\section{Acknowledgment}

We would like to thank Tramaco GmbH (Germany) and INTERDIST Kft. for the Tracel IM 3170 MS foaming agent, the National Office for Research, Development and Innovation for the funds K-132462 and NVKP_16-1-2016-0012 and János Bolyai Research Scholar-ship of the Hungarian Academy of Sciences.

\section{References}

[1] PlasticsEurope: Plastics - the facts 2019: An analysis of European plastics production, demand and waste data, (2020).

[2] Plastics Insight: Polylactic Acid Properties, Production, Price, Market and Uses. (accessed on: 2020.12.12.)

https://www.plasticsinsight.com/resin-intelligence/resin-prices/polylactic-acid/

[3] Edmund H. I., Herman F. M.: Principles of Plasticization In: Plasticization and Plasticizer Processes (eds.: Platzer N. A. J.) American Chemical Society, Philadelphia, USA, Vol 1, (1965).

[4] Pillin I., Montrelay N., Grohens Y.: Thermo-mechanical characterization of plasticized PLA: Is the miscibility the only significant factor? Polymer, 47/13. (2006) 4676-4682.

https://doi.org/10.1016/j.polymer.2006.04.013

[5] Kulinski Z., Piorkowska E.: Crystallization, structure and properties of plasticized poly(l-lactide). Polymer, 46/23. (2005) 10290-10300. https://doi.org/10.1016/j.polymer.2005.07.101

[6] Lee S.-T., Park C. B.: Foam Extrusion: Principles and Practice. CRC Press, Boca Raton (2014).

[7] Kolstad J. J., Vink E. T. H., Wilde D. B., Debeer L.: Assessment of anaerobic degradation of Ingeo polylactides under accelerated landfill conditions. Polymer Degradation and Stability, 97. (2012) 1131-1141.

https://doi.org/10.1016/j.polym degradstab.2012.04.003 
[8] Huang C., Thomas N. L.: Fabricating porous poly(lactic acid) fibres via electrospinning. European Polymer Journal, 99. (2018) 464-476. https://doi.org/10.1016/j.eurpolymj.2017.12.025

[9] Kmetty Á., Litauszki K., Réti D.: Characterization of Different Chemical Blowing Agents and Their Applicability to Produce Poly(Lactic Acid) Foams by Extrusion. Applied Sciences, 8. (2018) 1-17. https://doi.org/10.3390/app8101960

[10] Litauszki K., Kmetty Á.: Characterization of chemically foamed poly(lactic acid). In: ,OATK. Balatonkenese, Materials Science and Engineering 903. (2020) 012018.

https://doi.org/10.1088/1757-899X/903/1/012018

[11] Xu X., Park C. B., Xu D., Pop-Iliev R.: Effects of die geometry on cell nucleation of PS foams blown with $\mathrm{CO}_{2}$. Polymer Engineering \& Science, 43/7. (2003) 1378-1390.

https://doi.org/10.1002/pen.10117

[12] Sinclair R. G.: The Case for Polylactic Acid as a Commodity Packaging Plastic. Journal of Macromolecular Science, Part A, 33. (1996) 585-597. https://doi.org/10.1080/10601329608010880

[13] Martin O., Avérous: L.: Poly(lactic acid): plasticization and properties of biodegradable multiphase systems. Polymer, 42/14. (2001) 6209-6219. https://doi.org/10.1016/S0032-3861(01)00086-6

[14] Julien J., Bénézet J., Lafranche E., Quantin J., Bergeret A., Lacrampe M., Krawczak P.: Development of poly(lactic acid) cellular materials: Physical and morphological characterizations. Polymer, 53/25. (2012) 5885-5895.

https://doi.org/10.1016/j.polymer.2012.10.005 